\title{
Daintain/AIF-1 accelerates the activation of insulin-like growth factor-1 receptor signaling pathway in HepG2 cells
}

\author{
SHAOHUI JIA ${ }^{1}$, ZHONGXIA DU ${ }^{2}$, HUA JIANG ${ }^{2}$, XINGYUAN HUANG $^{3}$, \\ ZHENGWANG CHEN $^{2}$ and NING CHEN ${ }^{1}$ \\ ${ }^{1}$ College of Health Science, Wuhan Sports University, Wuhan, Hubei 430079; ${ }^{2}$ Key Laboratory of Molecular Biophysics \\ of the Ministry of Education, College of Life Science and Technology, Huazhong University of Science and Technology, \\ Wuhan, Hubei 430074; ${ }^{3}$ School of Life Science and Technology, Hubei Engineering University, \\ Xiaogan, Hubei 432000, P.R. China
}

Received January 30, 2015; Accepted April 9, 2015

DOI: $10.3892 /$ or.2015.4002

\begin{abstract}
Daintain/allograft inflammatory factor-1 (AIF-1), as a novel inflammatory factor, has been reported to accelerate the proliferation and migration of breast cancer cells. However, the effect of daintain/AIF-1 on hepatocarcinogenesis remains unclear. In order to explore the effect of daintain/AIF-1 on the progression of hepatocellular carcinoma (HCC), enzymelinked immunosorbent assay (ELISA) and reverse transcription polymerase chain reaction (RT-PCR) were performed to examine the secretion and gene expression of (IGF)-1, IGF-2 and IGFBP-3. The expression of IGF-1R and its downstream targets was evaluated by western blotting. In addition, the proliferation and cell-cycle progression of HepG2 cells was assessed by 3-(4,5-dimethylthiazol-2-yl)-2,5-diphenylterazolium bromide (MTT) and flow cytometric analysis. The results showed that HepG 2 cells subjected to daintain/AIF-1 treatment revealed an obvious increase in the secretion of IGF-1 and IGF-2, and a reduction in the secretion of IGFBP-3. Moreover, daintain/AIF-1 accelerated the activation of IGF-1-induced IGF-1R and its downstream AKT signaling pathway, and subsequently promoted the activation of cyclin D1 pathway, thus accelerating the progression of the cell cycle and eventually promoting the proliferation of HepG 2 cells. In conclusion, daintain/AIF-1 promoted the proliferation of HepG2 cells by accelerating the activation of IGF-1R and its downstream
\end{abstract}

Correspondence to: Professor Ning Chen, College of Health Science, Wuhan Sports University, 461 Luoyu Road, Wuhan, Hubei 430079, P.R. China

E-mail: nchen510@gmail.com

Professor Zhengwang Chen, Key Laboratory of Molecular Biophysics of the Ministry of Education, College of Life Science and Technology, Huazhong University of Science and Technology, 1037 Luoyu Road, Wuhan, Hubei 430074, P.R. China

E-mail: zwchen@mail.hust.edu.cn

Key words: insulin-like growth factor, hepatocellular carcinoma, cyclin D1, cell proliferation, daintain/AIF-1 signaling pathway, which confirms that daintain/AIF-1 plays a crucial role in the development of HCC.

\section{Introduction}

Hepatocellular carcinoma (HCC) is one of the most common lethal cancers worldwide (1). Following the diagnosis of liver cancer, approximately $20 \%$ patients benefit from curative surgical therapies such as liver resection and transplantation. Accumulating evidence has shown that insulin-like growth factors (IGF-1 and IGF-2) and their receptors (IGF-1R) are involved in the progression of cancers (2-5). The interaction between IGF-1 or IGF-2 and IGF-1R plays a pivotal role in tumorigenesis and the proliferation of cancer cells due to promotion of the cell-cycle progression (6). The mRNA expression level of IGF-1 in human HCC tissues is much lower than that in normal liver tissues, whereas, IGF-2 and IGF-1R reveal the overexpression in animal models of hepatocarcinogenesis and in HCC tissues (7). Mounting evidence confirms that the IGFs/IGF-1R axis is crucial in the development of $\operatorname{HCC}(7,8)$.

Daintain was first isolated from porcine intestine (9) and allograft inflammatory factor-1 (AIF-1) was first identified in heterotopic cardiac allografts of rats (10). Daintain has a high homology with AIF-1, thus this peptide has been deisgnated as as daintain/AIF-1. Daintain/AIF-1 can be constitutively expressed in monocytes and macrophages, and is involved in macrophage activation $(11,12)$. It plays a crucial role in many autoimmune diseases $(9,13-15)$. In previous studies, daintain/AIF-1 was confirmed to promote the proliferation and migration of breast cancer cells $(16,17)$. However, whether daintain/AIF-1 has any impact on the progression of HCC remain unknown.

The association of inflammation with cancer has been previously suggested (18). A clear example of inflammation-associated cancer is HCC. Although mounting evidence is gathered to explore its molecular mechanisms, an accurate molecular connection between inflammation and $\mathrm{HCC}$ remains elusive. It has been demonstrated that inflammatory factors such as TNF- $\alpha$, IL- 6 and IL- $\alpha$ contribute to the progression of HCC $(19,20)$. Daintain/AIF-1, as a novel inflammatory factor, has been found to be expressed in activated Kupffer 
Table I. Primer sequences and reaction conditions of RT-PCR.

\begin{tabular}{|c|c|c|c|c|}
\hline Genes & Primers & Sequences $\left(5^{\prime}-3^{\prime}\right)$ & Annealing temperature $\left({ }^{\circ} \mathrm{C}\right)$ & Cycle no. \\
\hline$I G F-1$ & $\begin{array}{l}\text { Forward } \\
\text { Reverse }\end{array}$ & $\begin{array}{l}\text { GCATTGTGGATGAGTGTTGC } \\
\text { GGCTCCTCCTACATTCTGTA }\end{array}$ & 53 & 30 \\
\hline$I G F-2$ & $\begin{array}{l}\text { Forward } \\
\text { Reverse }\end{array}$ & $\begin{array}{l}\text { GAGCTCGAGGCGTTCAGG } \\
\text { GTCTTGGGTGGGTAGAGCAATC }\end{array}$ & 58 & 30 \\
\hline$I G F B P-3$ & $\begin{array}{l}\text { Forward } \\
\text { Reverse }\end{array}$ & $\begin{array}{l}\text { ATATGGTCCCTGCCGTAGA } \\
\text { AAATCGAGGCTGAGCCAG }\end{array}$ & 55 & 30 \\
\hline$G A P D H$ & $\begin{array}{l}\text { Forward } \\
\text { Reverse }\end{array}$ & $\begin{array}{l}\text { CAAGGTCATCCATGACAACTTTG } \\
\text { GTCCACCACCCTGTTGCTGTAG }\end{array}$ & 56 & 25 \\
\hline
\end{tabular}

IGF, insulin-like growth factor; RT-PCR, reverse transcription polymerase chain reaction.

cells lining the walls of liver sinusoids $(21,22)$. Therefore, we hypothesized that daintain/AIF-1 may be involved in the development of HCC. Based on this hypothesis, the effects of daintain/AIF-1 on the activation of IGF-1R and its downstream signaling pathway in HepG2 cells were investigated. The results revealed that daintain/AIF-1 accelerated the activation of IGF-1-induced IGF-1R and its downstream signaling pathway.

\section{Materials and methods}

Reagents and antibodies. 3-(4,5-dimethylthiazol-2-yl)-2,5-diphenylterazolium bromide (MTT), propidium iodide (PI), Triton X-100 and recombinant human IGF-1 were all purchased from Sigma Chemical Co. (St. Louis, MO, USA). Recombinant human daintain/AIF-1 was prepared by our laboratory according to previous instructions (22). An Annexin V-FITC apoptosis detection kit was obtained from th eBiyuntian Institute of Biotechnology (Shanghai, China). Enzyme-linked immunosorbent assay (ELISA) kits were purchased from R\&D Systems (Minneapolis, MN, USA). Primary antibodies were purchased from Santa Cruz Biotechnology, Inc. (Santa Cruz, CA, USA).

Cell line and culture. HepG2 cells were purchased from the China Center for Type Culture Collection (CCTCC) and cultured into Dulbecco's modified Eagle's medium (DMEM; Gibco, Grand Island, NY, USA) supplemented with $10 \%$ (v/v) fetal bovine serum (FBS), $100 \mathrm{U} / \mathrm{ml}$ penicillin and $100 \mathrm{mg} / \mathrm{l}$ streptomycin at $37^{\circ} \mathrm{C}$ in an incubator supplied with $5 \% \mathrm{CO}_{2}$.

Secretion of IGF-1, IGF-2 and IGFBP-3. HepG2 cells were plated in 6-well plates and incubated with daintain/AIF-1 at various concentrations in serum-free medium for $72 \mathrm{~h}$. The cell supernatants were then collected to examine the secretion of IGF-1, IGF-2 and IGFBP-3 using commercial ELISA kits.

Reverse transcription polymerase chain reaction (RT-PCR) analysis. Total RNA was isolated using TRIzol reagent (Invitrogen, Carlsbad, CA, USA) and reversely transcribed to cDNA using a RevertAid ${ }^{\mathrm{TM}}$ cDNA Synthesis kit (Fermentas, Vilnius, Lithuania) according to the manufacturer's instructions. The primer sequences and reaction conditions of $I G F-1, I G F-2, I G F B P-3, I G F-1 R$ and $G A P D H$ are shown in Table I. The PCR products were evaluated by $2 \%$ agarose gel electrophoresis.

Western blot analysis. Cell samples were lysed in $20 \mu \mathrm{l}$ cell lysis buffer containing $1 \mathrm{mM}$ PMSF. The extracted proteins were separated by $12 \%$ SDS-PAGE and transferred to PVDF membrane by 2-h electroblotting. The blots were blocked in $5 \%$ non-fat dry milk for $1 \mathrm{~h}$ at room temperature, and then incubated overnight with corresponding primary antibodies at $4^{\circ} \mathrm{C}$. The membrane was washed with TBS containing $0.05 \%$ Tween-20 (TBS-T) three times and incubated with horseradish peroxidase-conjugated secondary antibodies for $1 \mathrm{~h}$ at room temperature. The blots were then developed with the enhanced chemiluminescence (ECL) kit (Pierce Biotechnology, Rockford, IL, USA). The optical density of the protein bands was assessed using Image $\mathbf{J}$ software.

Cell proliferation assays. Cell proliferation was evaluated by an MTT assay. For the MTT assay, the cells were plated in 96-well plates at a density of $2.5 \times 10^{3}$ cells/well and incubated overnight with standard culture medium. The cells were then starved for $24 \mathrm{~h}$ in serum-free medium. After 24-h cell culture, the original medium was replaced with fresh serum-free medium containing $40 \mu \mathrm{g} / \mathrm{l}$ IGF-1 in the presence or absence of daintain/AIF-1. After incubation for another $24 \mathrm{~h}$, the medium was replaced with $100 \mu 1 \mathrm{MTT}(0.5 \mathrm{mg} / \mathrm{ml})$ and incubated at $37^{\circ} \mathrm{C}$ for $4 \mathrm{~h}$. After $4 \mathrm{~h}$, the MTT solution was removed and $100 \mu \mathrm{l}$ DMSO was added into each well. After agitation for $10 \mathrm{~min}$, the absorbance of each well was measured by a microplate reader (Tecan Sunrise, Salzburg, Austria) at a wavelength of $570 \mathrm{~nm}$.

Cell cycle analysis. In order to investigate the distribution of the cell cycle, HepG2 cells were seeded in 6-well plates at a density of $1 \times 10^{6} \mathrm{cells} /$ well. After adhesion, the cells were starved for $24 \mathrm{~h}$ in serum-free DMEM. The original medium was then replaced with fresh serum-free medium containing $40 \mu \mathrm{g} / 1$ IGF-1 in the presence or absence of daintain/AIF-1. After incubation for $24 \mathrm{~h}$, the cells were collected and analyzed by flow cytometer (FC500; Beckman Coulter, La Brea, CA, USA). 
A
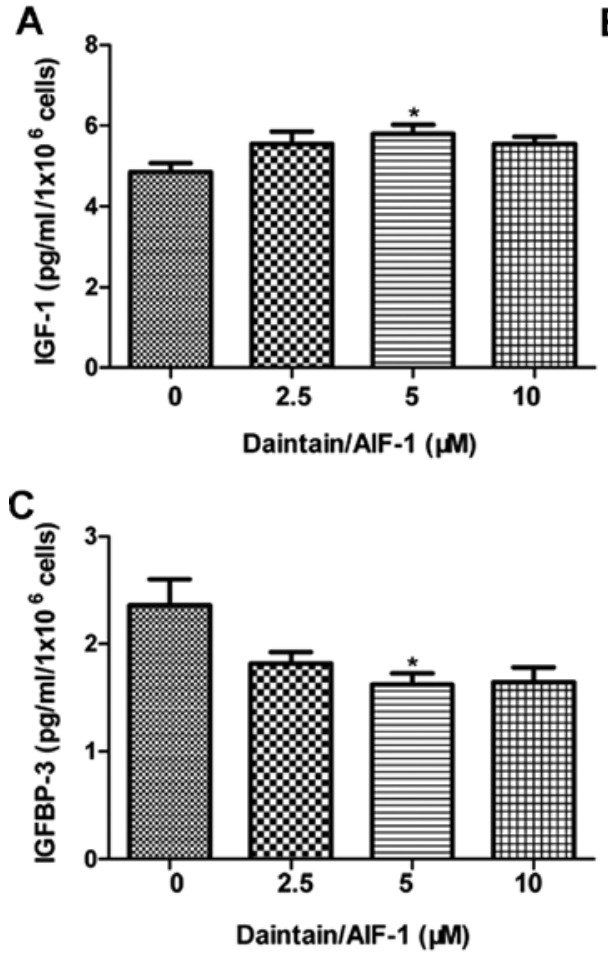

B

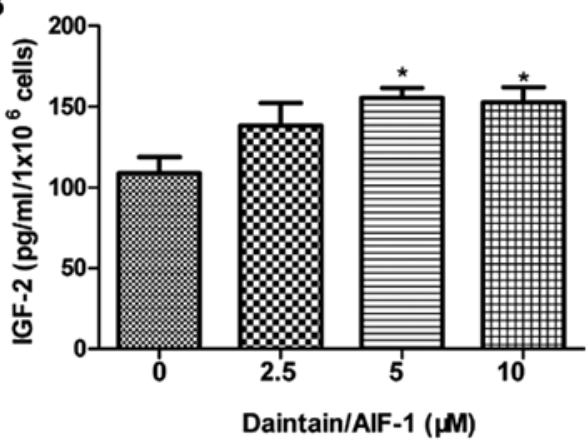

D

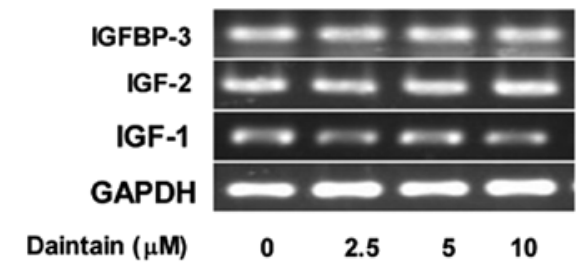

Figure 1. Daintain/AIF-1 accelerates the secretion of IGF-1, IGF-2 and IGFBP-3 in HepG2 cells, but has no impact on their gene expression. HepG2 cells were treated with daintain/AIF-1 at designated concentrations for $72 \mathrm{~h}$ in serum-free medium. Then, cell-free medium was collected to assess the secretion of (A) IGF-1, (B) IGF-2) and (C) IGFBP-3 by commercial ELISA kits. The mRNA expression of IGF-1, IGF-2 and IGFBP-3 (D) in daintain/AIF-treated cells was evaluated. Data were presented as mean \pm SD. A significant difference was considered at * $\mathrm{P}<0.05$ when compared with the control. AIF-1, allograft inflammatory factor-1; ELISA, enzyme-linked immunosorbent assay; IGF, insulin-like growth factor.

Statistical analysis. The experiments were repeated at least three times. The data were presented as mean \pm SD and calculated using the Student's t-test using GraphPad Prism version 5.0 (GraphPad Software, San Diego, CA, USA). A statistically significant difference was considered at $\mathrm{P}<0.05$.

\section{Results}

Daintain/AIF-1 promotes the secretion of IGF-1, IGF-2 and IGFBP-3 in HepG2 cells, but fails to modulate their gene expression. Accumulating data have demonstrated that alteration of the autocrine/paracrine loops involving IGFs and IGFBP-3 is associated with the proliferation of HCC cells $(8,23-25)$. Therefore, we examined the effects of daintain/AIF-1 on the production of IGFs and IGFBP-3 in the present study. Enhanced secretion of IGF-1 and IGF-2 was observed due to the stimulation of daintain/AIF-1 (Fig. 1A and B). By contrast, daintain/AIF-1 at the concentration of $5 \mu \mathrm{M}$ obviously decreased the secretion of IGFBP-3 (Fig. 1C). However, semi-quantitative RT-PCR analysis clearly showed that daintain/AIF-1 had no obvious effect on the gene expression of IGF-1, IGF-2 and IGFBP-3 (Fig. 1D).

Daintain/AIF-1 accelerates the activation of IGF-1-induced $I G F-1 R$ in HepG2 cells. Western blot analysis was conducted to examine the effect of daintain/AIF-1 on the IGF-1-induced activation of IGF-1R. As shown in Fig. 2A and C, IGF-1 induced an obvious phosphorylation of IGF-1R and daintain/AIF-1 accelerated IGF-1-induced activation of IGF-1R in a dose-dependent manner (Fig. 2B and D). Similarly, the increased level of phospho-IGF-1R was observed due to the co-incubation of IGF-1 and daintain/AIF-1. HepG2 cells treated with IGF-1 $(40 \mu \mathrm{g} / \mathrm{l})$ for $3 \mathrm{~h}$ in the presence of $5 \mu \mathrm{M}$ daintain/AIF-1 resulted in the maximum increase in phosphoIGF-1R.

Daintain/AIF-1 enhances the activation of IGF-1-induced $I G F-1 R$ downstream signaling pathway in HepG2 cells. To determine the role of daintain/AIF-1 in the activation of IGF-1-induced IGF-1R, activation of the downstream signaling pathway of IGF-1R was also examined by western blot analysis. Consistent with the results shown in Fig. 3, IGF-1 enhanced the expression of phospho-AKT, which was further promoted by daintain/AIF-1 in a dose-dependent manner. Similarly, daintain/AIF-1 at the increasing concentration resulted in an elevated expression of phospho-pS6K1. Moreover, in the presence of IGF-1, daintain/AIF-1 stimulation enhanced the expression of cyclin D1, CDK4 and phosphorylated Rb, but had no effect on the expression of cyclin E although IGF-1 alone resulted in an increased expression of cyclin $\mathrm{E}$.

Daintain/AIF-1 promotes IGF-1-induced proliferation of HepG2 cells. As shown in Fig. 4A, IGF-1 significantly accelerated the cell growth (115\% of the control) and daintain/AIF-1 promoted IGF-1-induced cell proliferation. The flow cytometric analysis revealed that IGF-1 stimulation decreased the proportion of HepG2 cells in the G0/G1 phase (from $67.7 \pm 5.4$ to $54.0 \pm 5.1 \%$ ), but increased the proportion 
A
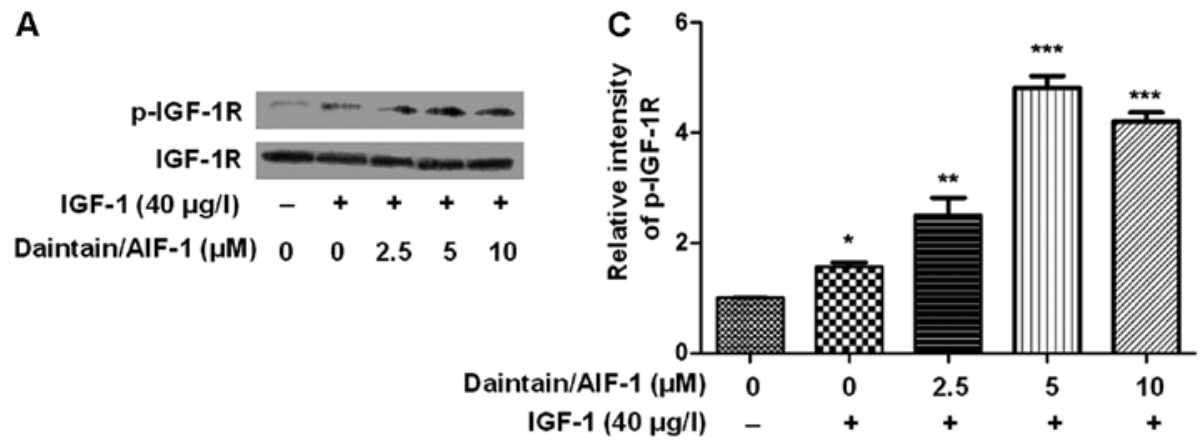

B
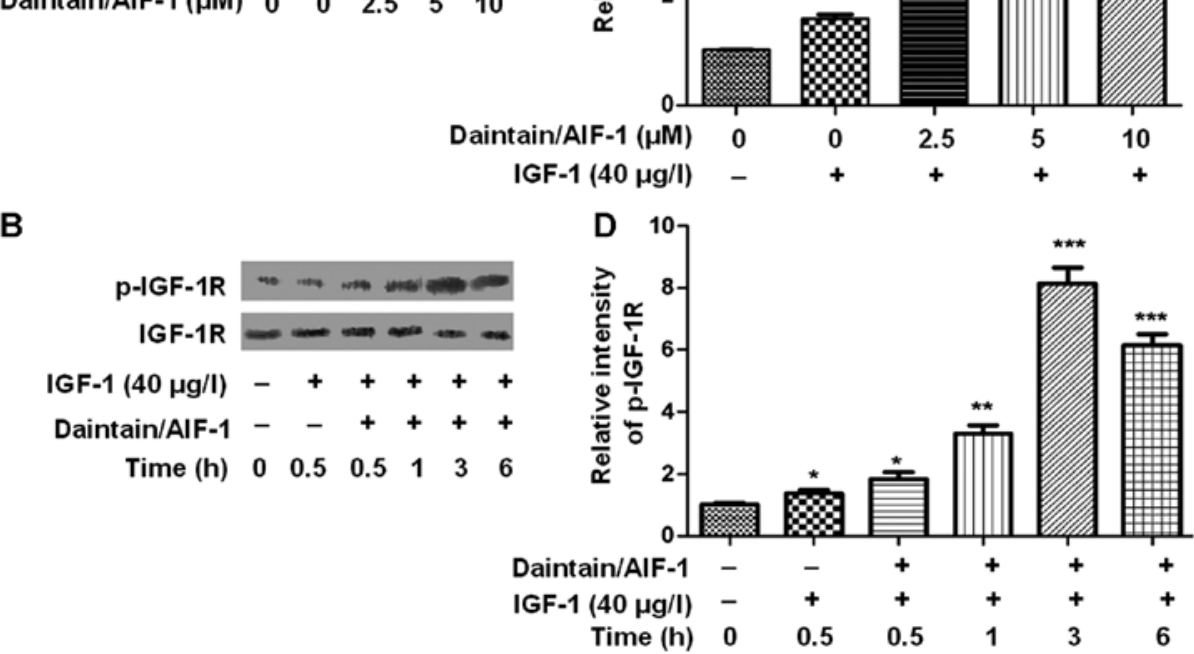

Figure 2. Daintain/AIF-1 accelerates the activation of IGF-1R and its downstream signaling pathways in the presence of IGF-1. HepG2 cells were treated with daintain/AIF-1 at the designated concentrations for $24 \mathrm{~h}$ in serum-free medium. The daintain/AIF-1-treated HepG2 cells were then stimulated with $40 \mu \mathrm{g} / 1$ IGF-1 for another $15 \mathrm{~min}$ and collected to examine the protein expression levels of phospho-IGF-1R and total IGF-1R by (A) western blot analysis. The relative expression or fold-changes of phosphor-IGF-1R after 15 min IGF stimulation was statistically analyzed (C) by measuring the optical density of the protein bands using Image J software. The daintain/AIF-1-treated HepG2 cells were then incubated with $40 \mu \mathrm{g} / 1$ IGF-1 at various time-points and the expression levels of phospho-IGF-1R and total IGF-1R were evaluated by western blot analysis (B). The relative expression or fold-changes of phosphor-IGF-1R during IGF-1 stimulation at various time-points was statistically analyzed (D) by measuring the optical density of protein bands using Image J software. AIF-1, allograft inflammatory factor-1; IGF, insulin-like growth factor. Data were expressed as mean $\pm \mathrm{SD}$, and asterisks indicated the statistically significant differences $\left({ }^{*} \mathrm{P}<0.05,{ }^{* *} \mathrm{P}<0.01\right.$ and $\left.{ }^{* * *} \mathrm{P}<0.001\right)$ when compared with the control.

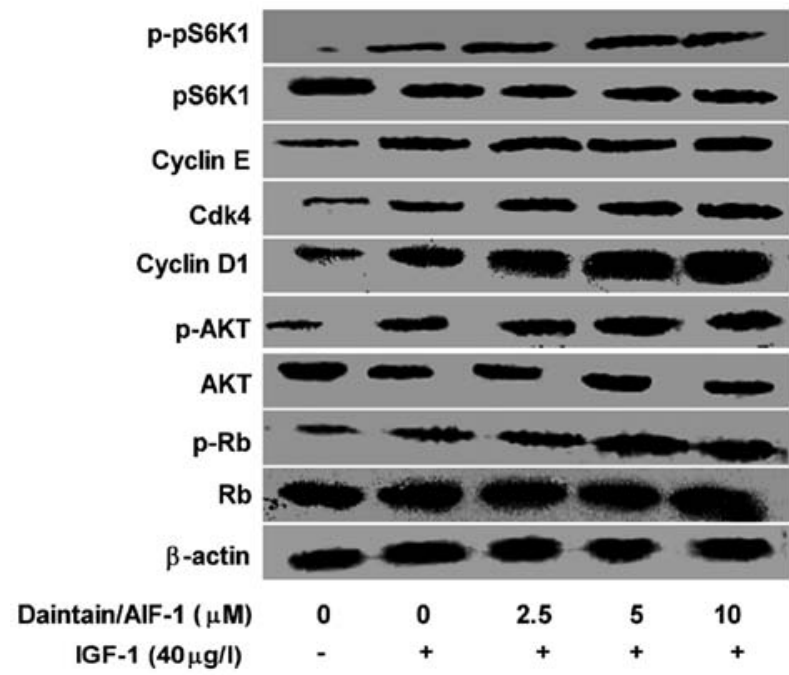

Figure 3. HepG2 cells were treated with daintain/AIF-1 at designated concentrations for $24 \mathrm{~h}$ in serum-free medium and then incubated with $40 \mu \mathrm{g} / 1$ IGF-1 for another $3 \mathrm{~h}$. After treatment, the cell proteins were isolated and subjected to the examination of downstream targets of IGF-1R such as p-AKT, p-pS6K1, p-Rb, cyclin E and D1 and CDK4 by western blot analysis. AIF-1, allograft inflammatory factor-1; ELISA, enzyme-linked immunosorbent assay; IGF, insulin-like growth factor.

of HepG2 cells in $\mathrm{S}$ phase (from $21.9 \pm 1.4$ to $31.5 \pm 2.8 \%$ ) and $\mathrm{G} 2 / \mathrm{M}$ phase (from $12.1 \pm 2.4$ to $14.3 \pm 3.0 \%$ ) (Fig. 4B). More significant changes in the cell cycle were observed due to the combinatorial application of daintain/AIF-1 and IGF-1. In the presence of IGF-1 $(40 \mu \mathrm{g} / \mathrm{l})$, daintain/AIF-1 reduced the ratio of HepG2 cells in the G0/G1 phase and enhanced the proportion of HepG 2 cells in the $S$ and $G 2 / M$ phase in a dose-dependent manner (Fig. 4B).

$I G F-1 R$ is involved in the promotion of daintain/AIF-1 on IGF-1-induced HepG2 cell proliferation. To confirm whether IGF-1R plays a role in the promotion of daintain/AIF-1 on the IGF-1-induced proliferation of HepG2 cells, the anti-IGF-1R antibody was used to suppress the expression of IGF-1R. The results showed that the anti-IGF-1R neutralizing antibody decreased the proliferation of HepG 2 cells under the induction of IGF-1. Furthermore, the promotion effect of daintain/AIF-1 on IGF-1-induced cell proliferation was eliminated due to the blockage of IGF-1R. Of note, after the blockage of IGF-1R, treatment of HepG2 cells with daintain/AIF-1 only caused a slight increase in the cell number (Fig. 5).

\section{Discussion}

Although previous findings have demonstrated that daintain/AIF-1 promotes breast cancer cell proliferation via the activation of the NF- $\kappa \mathrm{B} /$ cyclin D1 pathway, (16) the precise mechanisms of daintain/AIF-1 for promoting cancer cell proliferation are not completely understood. In the present study, we employed HepG2 cell lines to investigate the 
A

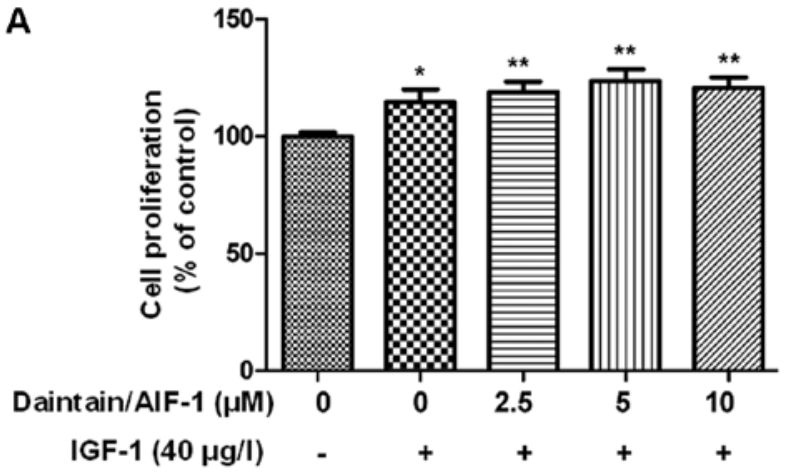

B

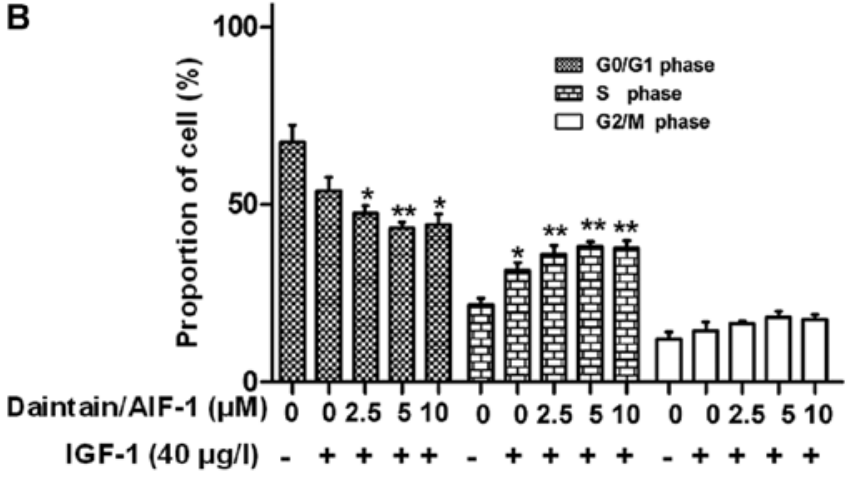

Figure 4. Daintain/AIF-1 promotes IGF-1-induced HepG2 cell proliferation and cell-cycle progression. (A) Cell proliferation was analyzed by MTT. (B) The distribution of the cell cycle was analyzed by flow cytometry. Data are presented $\S$ as mean $\pm \mathrm{SD}$, and asterisks indicated the statistically significant differences $\left({ }^{*} \mathrm{P}<0.05\right.$, and $\left.{ }^{* *} \mathrm{P}<0.01\right)$ when compared with the control. AIF-1, allograft inflammatory factor-1; IGF, insulin-like growth factor.

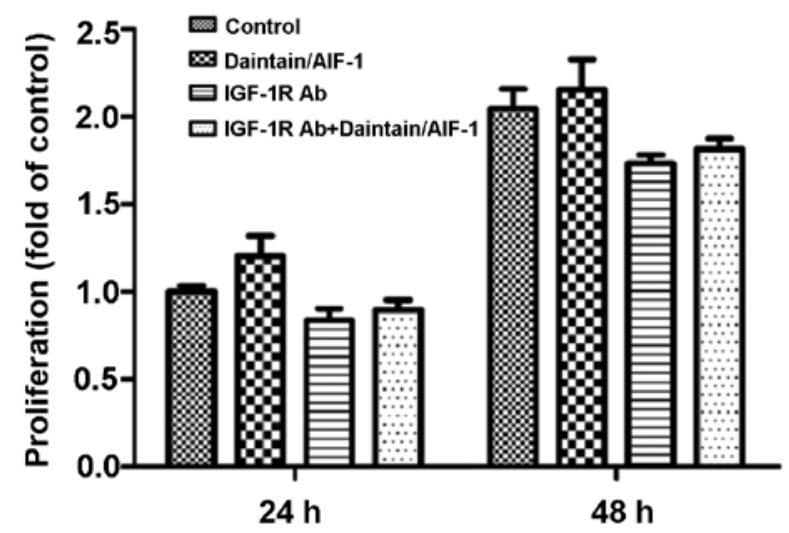

Figure 5. The blockage of IGF-1R inhibits IGF-1-induced HepG2 cell proliferation and eliminates the promotion effect of daintain/AIF-1 on IGF-1-induced HepG2 cell proliferation. HepG2 cells were treated with daintain/AIF-1 $(5 \mu \mathrm{M})$ or anti-IGF-1R antibody $(10 \mathrm{ng} / \mathrm{ml})$ alone for 24 and $48 \mathrm{~h}$, or a combinatorial application of daintain/AIF-1 and anti-IGF-1R antibody for 24 and $48 \mathrm{~h}$. Subsequently, $40 \mu \mathrm{g} / \mathrm{l} \mathrm{IGF-1} \mathrm{was} \mathrm{incubated} \mathrm{with} \mathrm{the}$ pretreated cells for another $3 \mathrm{~h}$. Following treatment, the cells were collected to analyze the cell proliferation by MTT assay. AIF-1, allograft inflammatory factor-1; IGF, insulin-like growth factor.

molecular mechanism of daintain/AIF-1 on promoting cell proliferation. Our results showed that daintain/AIF-1 is closely associated with the activation of IGF-1-induced IGF-1R and its downstream signaling pathway.
The IGF/IGF-1R axis has been previously found to play a critical role in the development of $\operatorname{HCC}(3,7,8)$. IGF-1R is predominantly activated by its ligands, such as IGF-1 and IGF-2. The bioactivity of IGFs can be modulated by IGFBPs due to the high affinity to IGF-1 and IGF-2 (26). IGFBPs can sequester IGF from IGF-1R, thereby attenuating the bioactivity of these growth factors. IGFBP-3 accounts for the majority of circulating IGF $(3,27,28)$. Treatment of HCC cells with recombinant IGFBP-3 can lead to a significant reduction in cell proliferation by inhibiting the activation of IGF-1-induced IGF-1R, ERK and AKT signaling pathways (23). In our study, daintain/AIF-1 enhanced the secretion of IGF-1 and IGF-2, reduced the secretion of IGFBP-3, but had no impact on their gene expression. On the basis of these results, daintain/AIF-1 may be involved in the activation of IGF-1R signaling pathway in HepG2 cells through the elevated IGF-1 and IGF-2.

The activation of IGF-1R is a vital process in the promotion of cell proliferation. Therefore, we monitored IGF-1-induced activation of IGF-1R in the presence of daintain/AIF-1 by western blot analysis. Treatment of HepG2 cells with daintain/ AIF-1 for 24 h significantly enhanced IGF-1-induced tyrosine phosphorylation of IGF-1R in a dose- and time-dependent manner.

When IGF-1R is stimulated, the tyrosine kinase activates its downstream signaling pathways, including the Ras/MAPK and PI3K/AKT pathways. The phosphorylation of MAPK can induce a subsequent increase in cell proliferation, and the activation of PI3K/AKT can lead to the modulation of mammalian target of rapamycin (mTOR), thus resulting in translational adaptation (29-31). mTOR can regulate cyclin D1 expression and Rb phosphorylation, and the inhibition of mTOR can arrest cells in the G0/G1 phase of the cell cycle $(32,33)$. Based on our study, daintain/AIF-1 revealed an obvious enhancement on the IGF-1-induced phosphorylation of PI3K/AKT and its downstream target pS6K1. pS6K1 is a key downstream element of the AKT signaling pathway, and the de-phosphorylation of pS6K1 can block the G1 cell cycle progression (34). We have also demonstrated that the incubation of HepG2 cells with daintain/AIF-1 upregulated the expression of cyclin D1, CDK4 and phosphorylated Rb in the presence of IGF-1. Cyclin D1 is important in the transition from $\mathrm{G} 1$ to $\mathrm{S}$ phase $(35,36)$. Cyclin D1 can couple with CDK4 or CDK6 to form cyclin D1/CDK complexes, thus correspondingly resulting in the activation of CDKs and the phosphorylation of $\mathrm{Rb}(37,38)$. Hypophosphorylated $\mathrm{Rb}$ can abrogate the inhibitory effect of $\mathrm{Rb}$ on the cell-cycle progression and accelerate cell entry into the $S$ phase (39).

The physiological function of daintain/AIF-1 on promoting IGF-1-induced activation of the IGF-1R signaling pathway was confirmed by the MTT assay. The results showed that daintain/AIF-1 markedly promoted IGF-1-induced HepG2 cell proliferation. Data from the flow cytometric analysis also revealed that daintain/AIF-1 accelerated HepG2 cell entry into the $\mathrm{S}$ and G2/M phase, which is consistent with our previous observation that daintain/AIF-1 promoted cyclin D1 expression and $\mathrm{Rb}$ phosphorylation.

In our study, the blockage of IGF-1R using the antiIGF-1R antibody inhibited IGF-1-induced HepG2 cell proliferation and eliminated the promotion effect of daintain/ AIF-1 on IGF-1-induced HepG2 cell proliferation. These 
results suggest that the $\mathrm{IGF} / \mathrm{IGF}-1 \mathrm{R}$ signaling pathway plays a crucial role in the promotion function of daintain/ AIF-1 on IGF-1-induced HepG2 cell proliferation. However, daintain/AIF-1 may have other pathways to promote HepG2 cell proliferation besides the activation of IGF-1R signaling pathway. Moreover, we observed the accelerated migration of HepG2 cells in the presence of IGF-1. However, daintain/AIF-1 failed to modulate IGF-1-induced cell migration (data not shown).

Taken together, according to our current studies and knowledge, daintain/AIF-1 induces activation of the IGF/IGF-1R axis and its downstream signaling pathways by regulating IGF-1, IGF-2 and IGFBP-3 secretion and enhancing IGF-1R sensitivity in the presence of IGF-1 stimulation, thereby resulting in the proliferation of HepG2 cells. However, more studies are required to elucidate the exact mechanisms of daintain/AIF-1 involved in the activation of the IGF-1R signaling pathway and its downstream signaling pathways.

\section{Acknowledgements}

This study was supported by the National Science Foundation of China (grant no. 31370773 and 81172511) and the Chutian Scholar Program to N.C. from Education Department of Hubei Province.

\section{References}

1. Bosch FX, Ribes J, Díaz M and Cléries R: Primary liver cancer: worldwide incidence and trends. Gastroenterology 127 (Suppl 1): S5-S16, 2004.

2. LeRoith D and Roberts CT Jr: The insulin-like growth factor system and cancer. Cancer Lett 195: 127-137, 2003.

3. Pollak MN, Schernhammer ES and Hankinson SE: Insulin-like growth factors and neoplasia. Nat Rev Cancer 4: 505-518, 2004

4. Khandwala HM, McCutcheon IE, Flyvbjerg A and Friend KE: The effects of insulin-like growth factors on tumorigenesis and neoplastic growth. Endocr Rev 21: 215-244, 2000.

5. Baserga R: Oncogenes and the strategy of growth factors. Cell 79: 927-930, 1994.

6. Reynolds AR and Kyprianou N: Growth factor signalling in prostatic growth: significance in tumour development and therapeutic targeting. Br J Pharmacol 147 (Suppl 2): S144-S152, 2006.

7. Scharf JG and Braulke T: The role of the IGF axis in hepatocarcinogenesis. Horm Metab Res 35: 685-693, 2003.

8. Alexia C, Fallot G, Lasfer M, Schweizer-Groyer G and Groyer A: An evaluation of the role of insulin-like growth factors (IGF) and of type-I IGF receptor signalling in hepatocarcinogenesis and in the resistance of hepatocarcinoma cells against drug-induced apoptosis. Biochem Pharmacol 68: 1003-1015, 2004.

9. Chen ZW, Ahren B, Ostenson CG, Cintra A, Bergman T, Möller C, Fuxe K, Mutt V, Jörnvall $\mathrm{H}$ and Efendic S: Identification, isolation, and characterization of daintain (allograft inflammatory factor 1), a macrophage polypeptide with effects on insulin secretion and abundantly present in the pancreas of prediabetic BB rats. Proc Natl Acad Sci USA 94: 13879-13884, 1997.

10. Utans U, Arceci RJ, Yamashita Y and Russell ME: Cloning and characterization of allograft inflammatory factor-1: a novel macrophage factor identified in rat cardiac allografts with chronic rejection. J Clin Invest 95: 2954-2962, 1995.

11. Tian Y, Kelemen SE and Autieri MV: Inhibition of AIF-1 expression by constitutive siRNA expression reduces macrophage migration, proliferation, and signal transduction initiated by atherogenic stimuli. Am J Physiol Cell Physiol 290: C1083-C1091, 2006.

12. Yang ZF, Ho DW, Lau CK, Lam CT, Lum CT, Poon RT and Fan ST: Allograft inflammatory factor-1 (AIF-1) is crucial for the survival and pro-inflammatory activity of macrophages. Int Immunol 17: 1391-1397, 2005.
13. Kimura M, Kawahito Y, Obayashi H, Ohta M, Hara H, Adachi T, Tokunaga D, Hojo T, Hamaguchi M, Omoto A, et al: A critical role for allograft inflammatory factor-1 in the pathogenesis of rheumatoid arthritis. J Immunol 178: 3316-3322, 2007.

14. Del Galdo F, Maul GG, Jiménez SA and Artlett CM: Expression of allograft inflammatory factor 1 in tissues from patients with systemic sclerosis and in vitro differential expression of its isoforms in response to transforming growth factor beta. Arthritis Rheum 54: 2616-2625, 2006.

15. Pashenkov M, Efendic S, Zhu J, Zou LP, Ostenson CG and Mustafa M: Augmented expression of daintain/allograft inflammatory factor-1 is associated with clinical disease: dynamics of daintain/allograft inflammatory factor-1 expression in spleen, peripheral nerves and sera during experimental autoimmune neuritis. Scand J Immunol 52: 117-122, 2000.

16. Liu S, Tan WY, Chen QR, Chen XP, Fu K, Zhao YY and Chen ZW: Daintain/AIF-1 promotes breast cancer proliferation via activation of the NF-kappaB/cyclin D1 pathway and facilitates tumor growth. Cancer Sci 99: 952-957, 2008.

17. Li T, Feng Z, Jia S, Wang W, Du Z, Chen N and Chen Z: Daintain/AIF-1 promotes breast cancer cell migration by up-regulated TNF- $\alpha$ via activate p38 MAPK signaling pathway. Breast Cancer Res Treat 131: 891-898, 2012.

18. Balkwill $\mathrm{F}$ and Mantovani A: Inflammation and cancer: back to Virchow? Lancet 357: 539-545, 2001.

19. Naugler WE, Sakurai T,Kim S, Maeda S, Kim K, Elsharkawy AM and Karin M: Gender disparity in liver cancer due to sex differences in MyD88-dependent IL-6 production. Science 317: 121-124, 2007.

20. Fausto N, Campbell JS and Riehle KJ: Liver regeneration. Hepatology 43 (Suppl 1): S45-S53, 2006.

21. Nagakawa Y, Nomoto S, Kato Y, Montgomery RA, Williams GM, Klein AS and Sun Z: Over-expression of AIF-1 in liver allografts and peripheral blood correlates with acute rejection after transplantation in rats. Am J Transplant 4: 1949-1957, 2004.

22. Hirsch J, Hansen KC, Choi S, Noh J, Hirose R, Roberts JP, Matthay MA, Burlingame AL, Maher JJ and Niemann CU: Warm ischemia-induced alterations in oxidative and inflammatory proteins in hepatic Kupffer cells in rats. Mol Cell Proteomics 5: 979-986, 2006.

23. Huynh H, Chow PK, Ooi LL and Soo KC: A possible role for insulin-like growth factor-binding protein-3 autocrine/paracrine loops in controlling hepatocellular carcinoma cell proliferation. Cell Growth Differ 13: 115-122, 2002.

24. Aishima S, Basaki Y, Oda Y, Kuroda Y, Nishihara Y, Taguchi K, Taketomi A, Maehara Y, Hosoi F, Maruyama Y, et al: High expression of insulin-like growth factor binding protein-3 is correlated with lower portal invasion and better prognosis in human hepatocellular carcinoma. Cancer Sci 97: 1182-1190, 2006.

25. Lund P, Schubert D, Niketeghad F and Schirmacher P: Autocrine inhibition of chemotherapy response in human liver tumor cells by insulin-like growth factor-II. Cancer Lett 206: 85-96, 2004.

26. Firth SM and Baxter RC: Cellular actions of the insulin-like growth factor binding proteins. Endocr Rev 23: 824-854, 2002 .

27. Yakar S, Wu Y, Setser J and Rosen CJ: The role of circulating IGF-I: lessons from human and animal models. Endocrine 19: 239-248, 2002

28. Bach LA, Headey SJ and Norton RS: IGF-binding proteins - the pieces are falling into place. Trends Endocrinol Metab 16: 228-234, 2005.

29. Adams TE, Epa VC, Garrett TP and Ward CW: Structure and function of the type 1 insulin-like growth factor receptor. Cell Mol Life Sci 57: 1050-1093, 2000.

30. Butler AA, Yakar S, Gewolb IH, Karas M, Okubo Y and LeRoith D: Insulin-like growth factor-I receptor signal transduction: at the interface between physiology and cell biology. Comp Biochem Physiol B Biochem Mol Biol 121: 19-26, 1998.

31. Dearth RK, Cui X, Kim HJ, Hadsell DL and Lee AV: Oncogenic transformation by the signaling adaptor proteins insulin receptor substrate (IRS)-1 and IRS-2. Cell Cycle 6: 705-713, 2007.

32. Hashemolhosseini S, Nagamine Y, Morley SJ, Desrivières S, Mercep L and Ferrari S: Rapamycin inhibition of the G1 to $\mathrm{S}$ transition is mediated by effects on cyclin D1 mRNA and protein stability. J Biol Chem 273: 14424-14429, 1998. 
33. Chen Y, Knudsen ES and Wang JY: The RB/p107/p130 phosphorylation pathway is not inhibited in rapamycin-induced G1-prolongation of NIH3T3 cells. Oncogene 13: 1765-1771, 1996.

34. Gao N, Flynn DC, Zhang Z, Zhong XS, Walker V, Liu KJ, Shi X and Jiang BH: G1 cell cycle progression and the expression of G1 cyclins are regulated by PI3K/AKT/mTOR/p70S6K1 signaling in human ovarian cancer cells. Am J Physiol Cell Physiol 287: C281-C291, 2004.

35. Burkhart DL and Sage J: Cellular mechanisms of tumour suppression by the retinoblastoma gene. Nat Rev Cancer 8: 671-682, 2008.
36. Santamaria D and Ortega S: Cyclins and CDKS in development and cancer: lessons from genetically modified mice. Front Biosci 11: 1164-1188, 2006.

37. Malumbres $\mathrm{M}$ and Barbacid $\mathrm{M}$ : Cell cycle, $\mathrm{CDKs}$ and cancer: a changing paradigm. Nat Rev Cancer 9: 153-166, 2009.

38. Lindqvist A, Rodríguez-Bravo V and Medema RH: The decision to enter mitosis: feedback and redundancy in the mitotic entry network. J Cell Biol 185: 193-202, 2009.

39. Schuuring E, Verhoeven E, Mooi WJ and Michalides RJ: Identification and cloning of two overexpressed genes, U21B31/PRAD1 and EMS1, within the amplified chromosome 11 13 region in human carcinomas. Oncogene 7: 355-361, 1992. 